Technical Note

\title{
Low pressure solar thermal converter
}

\author{
Gerald Müller* \\ School of Civil Engineering and the Environment, University of Southampton, Highfield, Southampton SO17 1BJ, UK
}

\section{A R T I C L E I N F O}

\section{Article history:}

Received 11 December 2008

Accepted 9 April 2009

Available online 15 May 2009

\section{Keywords:}

Solar thermal

Low pressure

Hot-air engine

Heat engine

\begin{abstract}
A B S T R A C T
The current development of solar power converters with air as working fluid focuses mostly on concentrating collectors combined with hot-air engines, and on very low temperature solar tower concepts. Whilst concentrating collectors and Stirling engines need complex technology, solar tower converters have very low efficiencies and require large installations. Pressurized containers as energy converters offer the advantage of simplicity, but appear not to have been investigated in detail. In order to assess their performance potential, an idealised thermal pressure converter was analysed theoretically. Two improvements to increase the initially low efficiency derived from theory were found. Neglecting losses, maximum theoretical efficiencies ranged from $6.7 \%$ for a temperature difference of $60 \mathrm{~K}$ to $17.7 \%$ for a difference of $195 \mathrm{~K}$. The low pressure solar thermal converter appears to offer development potential for low-tech solar energy conversion.
\end{abstract}

(c) 2009 Elsevier Ltd. All rights reserved.

\section{Introduction}

Solar energy is an important renewable energy source. A wide variety of technologies to convert solar radiation into useful energy in form of heat or electricity have been developed, see e.g. the overview given in [1]. One particular field, the generation of mechanical power from solar heat using air as the transport fluid, has mostly focussed on two different development strands:

- Concentrating solar collectors and hot-air engines for high temperature differences [2-6].

- Solar updraft towers, which use very low temperature differences, e.g. [7].

The effective operation of hot-air engines requires temperature differences exceeding $600 \mathrm{~K}$ and, in case of the Stirling engine, a heat sink (or cold end) [5]. These engines offer good efficiencies, but the required temperatures can realistically only be reached with focusing arrangements. Low Temperature Differential (LTD) engines which operate with working temperatures of $307 \mathrm{~K}$ only achieved efficiencies of $0.44 \%$ [6]. The solar updraft concept comprises of a transparent roof under which air is heated, a chimney which draws the hot air upwards, and a turbine inside of the chimney. The concept has the advantage of being simple with comparatively small temperature increases

\footnotetext{
* Tel.: +44 2380592442 .

E-mail address: g.muller@soton.ac.uk
}

of the air in the range of $20-50 \mathrm{~K}$. A prototype was built and operated effectively at Manzanares/Spain. The main disadvantage of the solar updraft concept is the low efficiency. Larger towers are more effective, so that their economy depends on the size of the plant. Fig. 1a shows the principle, Fig. 1b, the efficiency as a function of tower height [7]. It can be seen that even for tower heights of $1000 \mathrm{~m}$, theoretical efficiencies only reach $3.8 \%$.

There is a need for simple, low maintenance, stand-alone solar energy converters for remote areas and/or developing countries. Such a machine would employ air as a working fluid since it simplifies the power conversion considerably. Both development strands described previously can probably not be expected to solve this particular problem.

The continuing interest in the solution of the problem of power generation from solar energy without complex technology is reflected in many suggestions for power converters made in the literature, which even include the power generation by a tethered hot-air balloon [8]. The principle of exploiting the pressure buildup of a heated fluid in a closed container has however attracted little attention; the main reason probably being the perceived low efficiencies. Such converters however potentially have the advantage of simplicity and resulting low costs. This note aims to investigate the theory of the ideal low pressure solar thermal converter in order to determine whether performance/development potential exists. At this stage, only passing attention is paid to the questions connected with the actual construction of such a converter. 

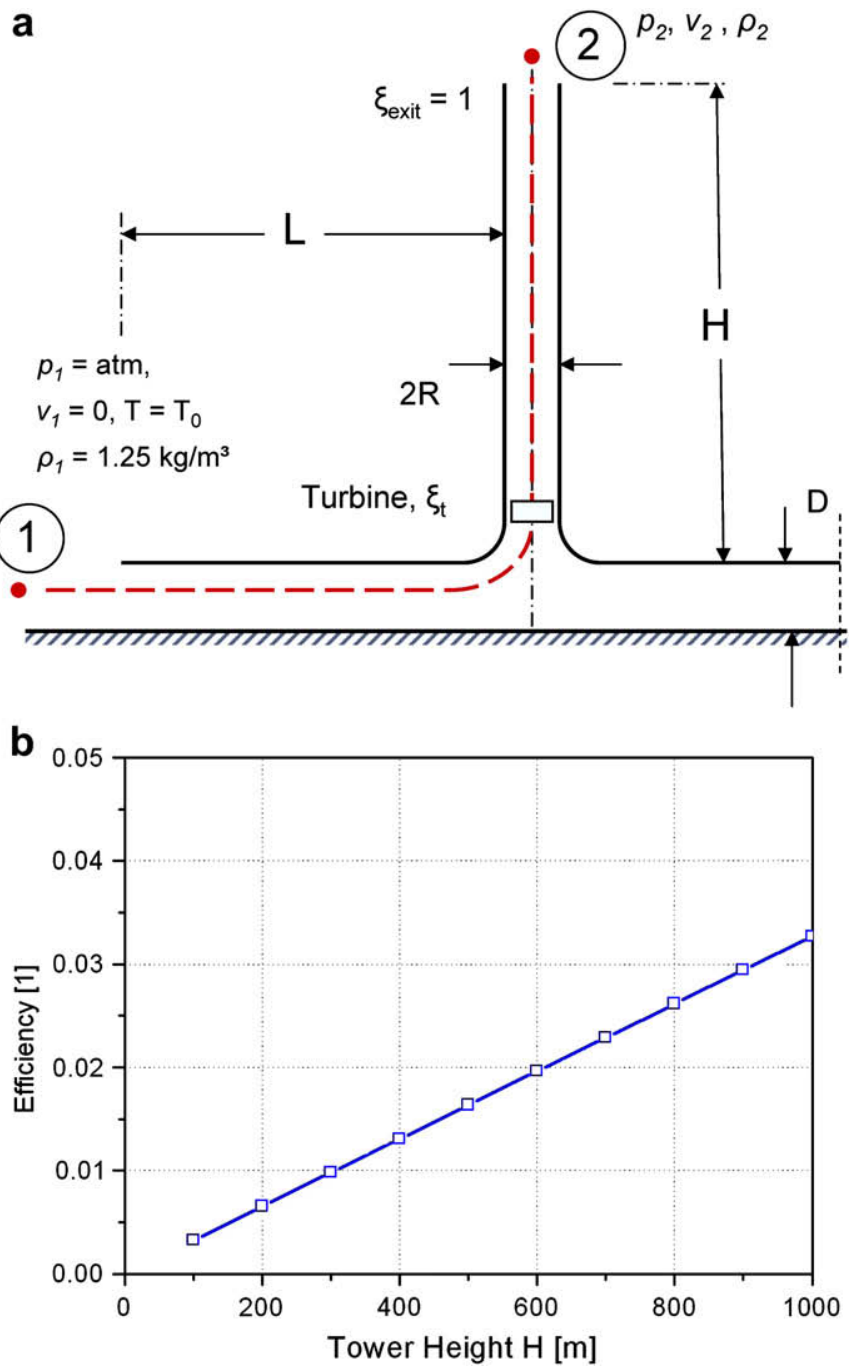

Fig. 1. The solar updraft tower. a. Principle of operation. b. Theoretical efficiency as function of tower height $H$.

\section{The Low Pressure Solar Thermal Converter (LPSTC)}

\subsection{Introduction}

Most concepts of mechanical power generation from solar energy, even the 'unconventional' ones, focus on the generation of rotational motion [4]. Solar pumps which produce single stroke motion using a variety of different principles were reported, but the potential of pumping action was apparently not explored further [4]. The requirement for rotary motion, which implies a continuous cycle, does however restrict the possibilities of solar power generation. Stepping away from the idea of continuous movement onto discrete motion machines, which generate power with strokes occurring at 'long' intervals, other concepts become possible and problems connected e.g. with time required for mass movement and heat transfer reduces.

\subsection{Principle}

The idealised LPSTC consists of a collector box, which also acts as a cylinder, with a piston on one side. The surface of the collector absorbs solar energy, whilst the sides and the bottom are insulated,
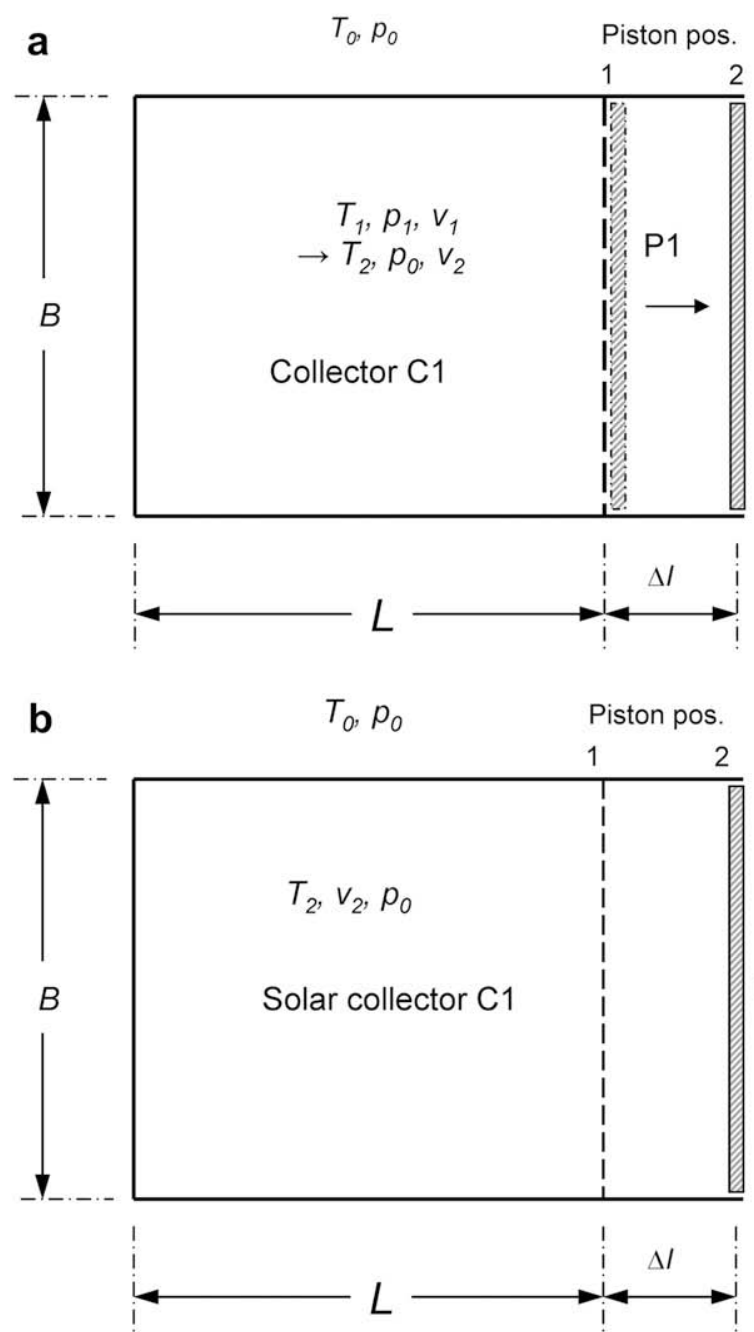

Piston P1

Fig. 2. Solar collector. a. Initial stage and adiabatic expansion. b. Expansion complete.

Fig. 2a. The air inside of the collector ' $\mathrm{C} 1$ ' has the initial volume $v_{0}$ at ambient temperature $T_{0}$, and is then heated up through solar radiation by a temperature difference $\Delta T$ to a temperature $T_{1}$. The volume $v_{1}=v_{0}$ of ' $C 1$ ' remains constant, the pressure increases to $p_{1}$ :

$p_{1}=\frac{T_{1}}{T_{0}} p_{0}$

A temperature increase of $120 \mathrm{~K}$ results in a pressure of $p_{1}=140 \mathrm{kPa}$, assuming $T_{0}=300 \mathrm{~K}, p_{0}=100 \mathrm{kPa}$ and a mass of $1 \mathrm{~kg}$, corresponding to a volume of $0.861 \mathrm{~m}^{3}$. Once the operating pressure $p_{1}$ is reached, the piston P1 is released and moves backwards to a distance $\Delta l=v_{2}-v_{1}$ until the ambient pressure $p_{0}$ is reached again, Fig. 2b. During the adiabatic expansion the volume of the heated air increases from $v_{1}$ to $v_{2}$, whilst the temperature reduces from $T_{1}$ to $T_{2}$. The expanded volume of the air can be calculated, with $\kappa$ as the adiabatic coefficient (air: $\kappa=1.4$ ):

$p_{1} \cdot v_{1}^{K}=p_{0} \cdot v_{2}^{K}$

With this, the thermal work $W_{\text {th }}$ from adiabatic expansion becomes (e.g. [9]):

$W_{\mathrm{th}}=\frac{1}{\kappa-1}\left(p_{1} \cdot v_{1}-p_{0} \cdot v_{2}\right)$ 


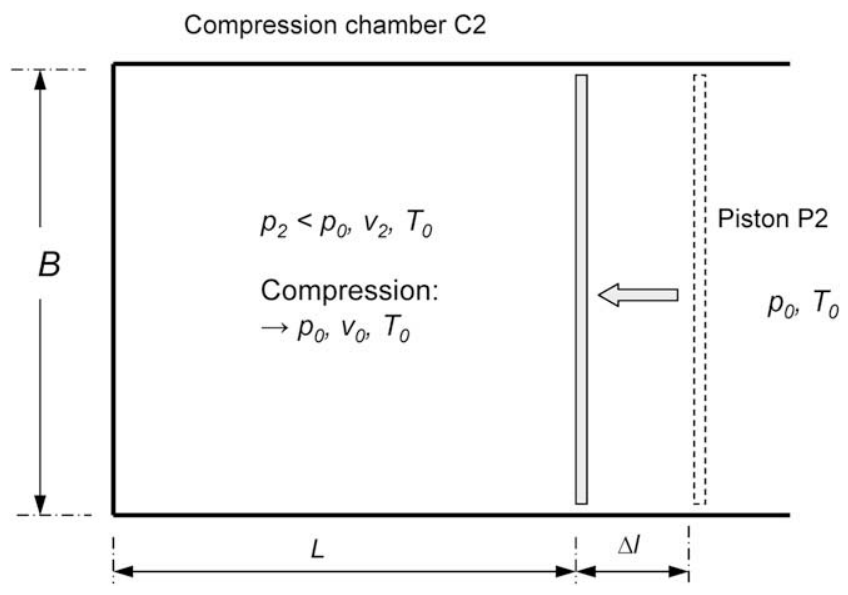

Fig. 3. Atmospheric compression (isothermal).

The actual useable work $W_{1}$ is the thermal work minus the atmospheric pressure component:

$W=W_{\text {th }}-p_{0} \cdot \Delta l$

With an initial pressure of $140 \mathrm{kPa}$, $\Delta l=1.096-0.861=0.235 \mathrm{~m}$, and the work $P_{1}=4.02 \mathrm{~kJ}$, whilst the temperature reduces to $T_{2}=381 \mathrm{~K}$.

In order for the air in the converter to initially reach the operating temperature $T_{1}$, the solar radiation must heat up to the air. With a thermal capacity of air $q_{\mathrm{v}}=0.717 \mathrm{~kJ} / \mathrm{kg} \mathrm{K}$ (constant volume), the total solar energy $E_{\mathrm{S}}$ required to reach $T_{1}$ is:

$E_{\mathrm{s}}=q_{\mathrm{v}} \cdot\left(T_{1}-T_{0}\right)$

The efficiency $\eta_{1}$ then becomes:

$\eta_{1}=\frac{W_{1}}{E_{\mathrm{S}}}$

For $\Delta T=120 \mathrm{~K}$, the efficiency only reaches $4.7 \%$.

\subsection{Improvement 1: atmospheric work}

The efficiency appears to be very low; energy is however still contained in the expanded air volume in form of the temperature difference $\Delta T_{2}=T_{1}-T_{2}$. This hot air is assumed to be pushed into a second cylinder C2 (located outside the solar collector), where it is cooled down to ambient temperature, Fig. 3. This results in a reduced pressure $p_{2}$ :

$p_{2}=\frac{p_{0} \cdot v_{1} \cdot T_{0}}{T_{2}}$

Once $p_{2}$ is reached, the piston P2 is released and thermal work generated. Since continuous cooling can be provided, the atmospheric work $W_{2}$ is isothermal

$W_{2}=p_{2} \cdot v_{2} \cdot \ln \left(p_{2} / p_{0}\right)+p_{0} \cdot\left(v_{2}-v_{1}\right)$

Note that the thermal work is negative in this situation. For an initial temperature of $T_{2}=381 \mathrm{~K}$, and a volume of $1.096 \mathrm{~m}^{3}$, this leads to the pressure $p_{2}$ to drop to $71.4 \mathrm{kPa}$ (absolute). The isothermal compression work $W_{2}$ reaches $2.7 \mathrm{~kJ}$, resulting in an improved efficiency $\eta_{1}=8.0 \%$.

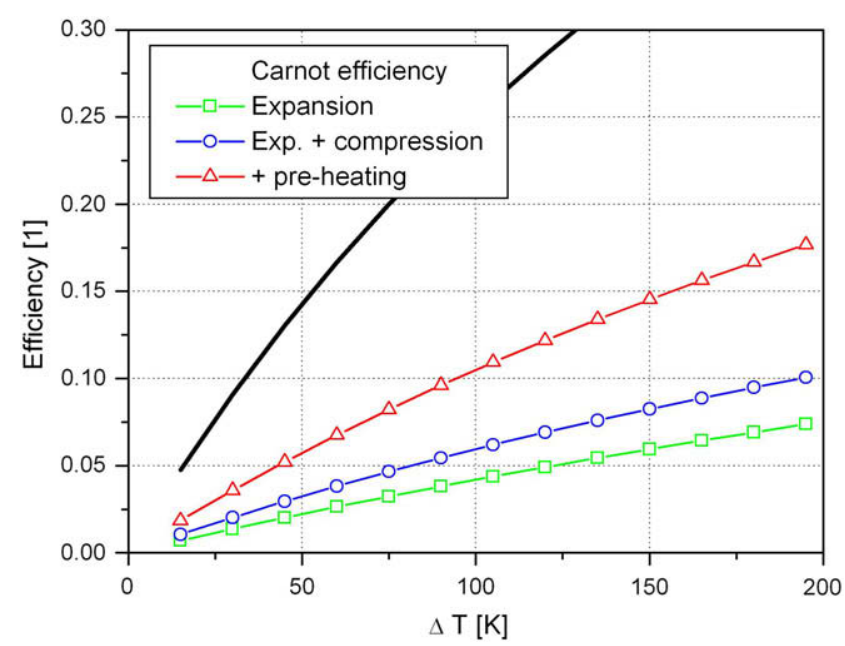

Fig. 4. Efficiencies for simple and improved case.

\subsection{Improvement 2: heat exchange}

The temperature of the expanded volume inside the 'cold' cylinder C2 has to be reduced from $T_{2}$ to $T_{0}$ in order to reduce the pressure. The thermal energy of the expanded air volume $v_{2}$ can be employed to pre-heat the new air, which has to be drawn into ' $\mathrm{C} 1$ ' from the atmosphere, from the initial ambient temperature $T_{0}$ to $T_{0}^{\prime}$ :

$T_{0}^{\prime}=\frac{T_{0}+T_{2}}{2}$

This reduces the energy requirement to reach the initial working temperature $T_{1}$ in C1. For $T_{0}=300 \mathrm{~K}$ and $T_{2}=381 \mathrm{~K}$, the temperature $T_{0}^{\prime}$ becomes $341 \mathrm{~K}$. The reduced solar energy $E_{\text {red }}$ required to reach $T_{1}$ is then:

$E_{\text {red }}=q_{\mathrm{v}} \cdot\left(T_{1}-T_{0}^{\prime}\right)$

And the improved theoretical efficiency $\eta_{2}$ becomes:

$\eta_{2}=\frac{W_{1}+W_{2}}{E_{\mathrm{red}}}$

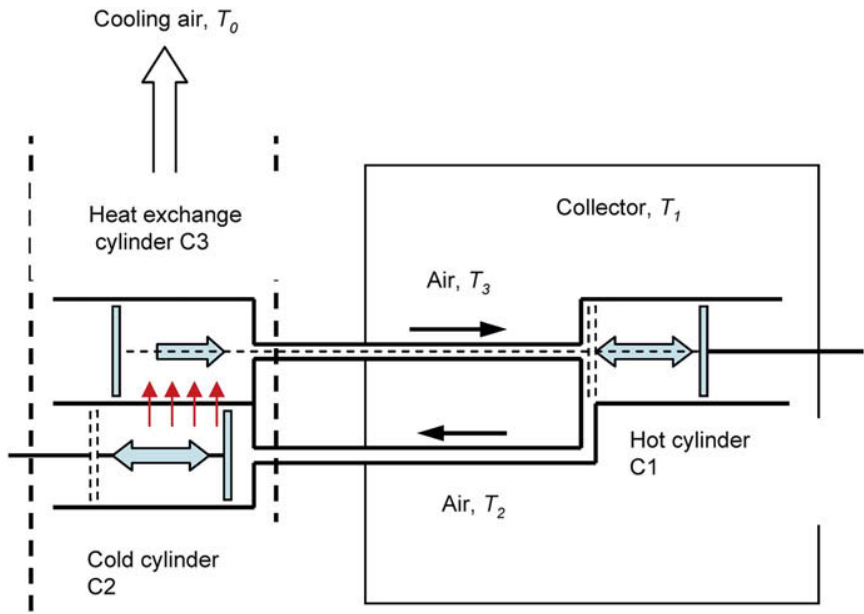

Fig. 5. Schematic of 'real' converter. 
This improves the efficiency for $\Delta T=120 \mathrm{~K}$ from 8.0 to $12.2 \%$; still well below the Carnot efficiency of $28.6 \%$.

Fig. 4 shows the efficiencies for the simple and improved cases; added is the Carnot efficiency. The efficiencies are significantly higher than those for the solar tower plant, reaching $17.7 \%$ for a temperature increase of $195 \mathrm{~K}$.

\subsection{The collector and power take-off}

A real LPSTC can be envisaged as a 'box inside a box' system where the cylinder is located inside an insulated wall structure with a glass roof. The collector serves as a heat reservoir of (nearly) constant temperature, so that the actual cylinder can be significantly smaller than the collector, Fig. 5 . The 'hot' cylinder $\mathrm{C} 1$ is connected with the 'cold' cylinder $\mathrm{C} 2$, which itself is located outside the collector in a draft chimney. The 'hot' cylinder C1 is heated up from the initial temperature $T_{0}$ to $T_{1}$. Once the 'hot' cylinder's working stroke has taken place, the air of temperature $T_{2}$ is pushed into the 'cold' cylinder C2. Attached to the 'cold' cylinder is the heat exchange cylinder $\mathrm{C} 3$, filled with air of ambient temperature which is then pre-heated by the air of temperature $T_{2}$ just drawn into the 'cold' cylinder. The temperature in $\mathrm{C} 3$ increases from $T_{0}$ to $T_{0}^{\prime}$ (whilst the temperature of the air in the cold cylinder reduces), the pressure also increases, and the air is then pushed into the 'hot' cylinder $\mathrm{C} 1$, to be heated up to the operating temperature $T_{1}$. The air in the draft chimney subsequently cools down the 'cold' cylinder to $T_{0}$, and its working stroke can occur. C3 and C1 are linked, so that (ideally) no work is required to move the now pressurized air. Numerical simulations showed that even without an external box, temperature differences of $100 \mathrm{~K}$ and more are possible [10]. The power generated by the working strokes can be used to pressurize a vessel containing air and water or pump water into a water tower which acts as energy storage; the high pressure water then drives a Pelton turbine. With this arrangement, the discrete motion of the converter can be distributed over time and thus utilized effectively.

\subsection{Available power}

Assuming a collector area of $A=25 \mathrm{~m}^{2}$, and a solar insolation of $1 \mathrm{~kW} / \mathrm{m}^{2}$, the theoretical power maximum (assuming no losses, a converter height of $0.5 \mathrm{~m}$ and a temperature difference of $120 \mathrm{~K}$ ) reaches $3.05 \mathrm{~kW}$ for a volume of $12.5 \mathrm{~m}^{3}$. With a piston volume of $0.861 \mathrm{~m}^{3}$, ideally one stroke of $0.235 \mathrm{~m}$ is required for every $7.6 \mathrm{~s}$.

\section{Discussion and conclusions}

The manuscript presented a theoretical investigation of a discrete motion low pressure solar thermal machine. The maximum theoretical efficiencies range from $6.7 \%$ for temperature differences of $60 \mathrm{~K}$ to $17.7 \%$ for $\Delta T=195 \mathrm{~K}$. These efficiencies are comparatively small, but significantly larger than those reported for the solar chimney. In addition, the proposed collector's efficiency is not dependent on size, so that modular construction becomes possible. The proposed box-inside-a box system implies that the working cylinder constitutes a heat sink, focusing the energy of the collector into it. The technology required is simple and may be costeffective; it does however require an intermediate energy storage such as a pressure vessel in order to utilise the discrete strokes of the machine. More generally speaking the proposed energy conversion mechanism could possible be termed an atmospheric Stirling cycle.

From the theoretical investigation the following conclusions can be drawn:

- The solar thermal pressure converter constitutes a simple, feasible concept with stand-alone capabilities.

- When an expansion stroke and pre-heating are added, the theoretical efficiencies are acceptable.

- A piston-type solar thermal converter may well have development potential.

\section{References}

[1] Philibert $C$. The present and future use of solar thermal energy as a primary source of energy. International Energy Agency Paper, http://www.iea.org/ Textbase/publications/free_new_Desc.asp?PUBS_ID=1574 2005 [accessed 04.12.08].

[2] Spencer LC. A comprehensive review of small solar-powered heat engines: part I: a history of solar powered devices up to 1950. Solar Energy 1989;43:191-6.

[3] Spencer LC. A comprehensive review of small solar-powered heat engines: part II: research since 1950-conventional engines up to $100 \mathrm{~kW}$. Solar Energy 1989;43:197-210.

[4] Spencer LC. A comprehensive review of small solar-powered heat engines: part III. Research since 1950 - unconventional" engines up to $100 \mathrm{~kW}$. Solar Energy 1989;43:211-25.

[5] Kongtragool B, Wongwises S. A review of solar-powered Stirling engines and low temperature differential Stirling engines. Renewable and Sustainable Energy Reviews 2003;7(2):131-54.

[6] Kongtragool B, Wongwises S. A four power-piston low-temperature differential Stirling engine using simulated solar energy as a heat source. Solar Energy 2008;82:493-500.

[7] Schlaich J, Bergemann B, Schiel W, Weinrebe G. Design of a commercial solar updraft tower systems - utilization of solar induced convective flows for power generation. Journal of Solar Energy Engineering 2005;127(1):117-24.

[8] Edmonds I. Hot air balloon engine. Renewable Energy 2009;34(4):1100-5.

[9] Dietzel F, Wagner W. Technische wärmelehre. 9th ed. Würzburg/Germany: Vogel Verlag; 2006.

[10] Knaggs S. Solar energy generation, final year project report, University of Southampton; 2007 [unpublished]. 